\title{
The challenge of extra-intra craniometry: a computer-assisted three-dimensional approach on the equine skull
}

\author{
A. Lang ${ }^{1}$, P. Brucker ${ }^{1}$, M. Ludwig ${ }^{1}$, T. Wrede ${ }^{2}$, J. Theunert ${ }^{2}$, H. Gasse ${ }^{1}$ \\ ${ }^{1}$ Institute of Anatomy, University of Veterinary Medicine Hannover, Hanover, Germany \\ ${ }^{2}$ Faculty II - Mechanical Engineering and Bio Process Engineering, University of Applied Sciences and Arts, \\ Hanover, Germany
}

[Received: 11 October 2016; Accepted: 8 November 2016]

Background: The topographical correlations between certain extracranial and intracranial osseous points of interest (POIs), and their age-related changes, are indispensable to know for a diagnostical or surgical access to intracranial structures; however, they are difficult to assess with conventional devices.

Materials and methods: In this pilot study, the 3-dimensional coordinates of extra-/intracranial POIs were determined, thus avoiding perspective distortions that used to be intrinsic problems in 2-dimensional morphometry. The data sets were then analysed by creating virtual triangles. The sizes, shapes, and positions of these triangles described the extent and the directions of the age-related shifts of the POIs. A selection of extracranial and intracranial POls were marked on half skulls of four warmblood horses in two age groups (young: 6 weeks, $n=2$; old: 14 and 17 years, $n=2$ ). The $x-, y$-, and $z$-coordinates of these $P O / s$ were determined with a measurement arm (FaroArm Fusion, FARO Europe ${ }^{\circledR}$ ). Direct distances between the POls as well as their indirect distances on the $x-, y-$, and $z$-axis, and angles were calculated.

Results: The analysed virtual triangles revealed that some parts of the skull grew in size, but did not change in shape/relative proportions (proportional type of growth, as displayed by $\mathrm{POI} A$ and $\mathrm{POI} B$ at the Arcus zygomaticus). The same $P O / s(A$ and $B$ ) remained in a very stable relationship to their closest intracranial $\mathrm{POI}$ at the Basis cranii on the longitudinal axis, however, shifted markedly in the dorso-lateral direction. In contrast, a disproportional growth of other parts of the cranium was, for example, related to POI C at the Crista nuchae, which shifted strongly in the caudal direction with age. A topographically stable reference point (so-called anchor point) at the Basis cranii was difficult to determine.

Conclusions: Two candidates (one at the Synchondrosis intersphenoidalis, another one at the Synchondrosis sphenooccipitalis) were relatively stable in their positions. However, the epicentre of (neuro-)cranial growth could only be pinpointed to an area between them. (Folia Morphol 2017; 76, 3: 458-472)

Key words: osseous landmarks, cranial cavity, horse, age, growth, size, geometry, shift, direction, triangles, anchor point, reference point

Address for correspondence: Dr. A. Lang, Institute of Anatomy, University of Veterinary Medicine Hannover, Bischofsholer Damm 15, D-30173 Hannover, Germany, tel: +49 511856 7368, fax: +49 51185682 7214, e-mail: anja.lang@tiho-hannover.de 


\section{INTRODUCTION}

The techniques applied in osteometry of the skull - although conventional in terms of measuring devices like rulers, slide gauges, and callipers [5, 11, 12 , 14] - have yielded very precise and most valuable data regarding the external surface of the skull. And yet, as emphasised by Brucker [1], these classical procedures were subject to an essential limitation: They were not able to perform similarly reliable measurements from a point at the outside of the skull to a point at its inside (unless bony structures had been removed). However, metrical data relating the outside to the inside may be desirable $[1,15]$ for a diagnostic or surgical access to intracranial neurological and/or vascular structures, even more so as stereotactic data for extra-intracranial manoeuvres on the equine skull are still lacking [1]. Consequently, first attempts have been made to cope with the challenge of extra-intra measurements by means of a computer-assisted, 3-dimensional (3D) measuring device [1]. (A similar device had been used for craniometry on canine skulls $[3,4]$, however, with exclusive attention to the exterior surface of the skulls.) In the present study, the demonstration of this promising technical tool is one of two major issues.

The second issue of this study is related to the fact that osteometrical studies on the equine skull have been performed for various purposes, e.g. archeozoological $[2,18,19]$ or ontogenetic ones [14, 22, 23], but with hardly any clinical focus on the location of the brain and its adjacent structures within the Cavum cranii. Within their intentional scope, these previous studies had focused either on the dimensions of the skull in relation to the dimensions of the bones of legs or trunk $[2,11]$, or they described the proportions of Facies and Cranium (Splanchno-/Viscerocranium and Neurocranium in older terminology) $[6,7,11,14,17$, $22,23]$, however, with very few measurements on the Cranium itself.

It is commonly known that the ontogenetic growth of the skull results in a marked change in the ratio of Facies to Cranium in horses, which is due to an abundant elongation of the Facies (i.e. Splanchno-/ Niscerocranium). So far, measurements on the relative extent of growth of the Cranium (i.e. Neurocranium) have yielded data on the length of the Basis cranii of perinatal foetuses and of very young newborn foals [14]. The variability of cranial morphology has been elaborated on in order to describe different constitution types of horses [11] with exclusive focus on certain extracranial landmarks (points of interest [POIs]); no particular attention has so far been paid to intracranial POIs. Accordingly, the ontogenetic shifts of different osseous landmarks at the inside of the Cranium and their topographical relations to external landmarks (or vice versa) have not yet been documented.

While some notion of the direction of such shifts during the growth process could be deduced from comparative evaluations of several measured distances on the equine Cranium [1], a much more specific method was elaborated on by Onar and Günes [16] in order to describe age-related changes in the skulls of dogs: A combination of three POls were connected by two lines forming an angle, which changed its size in relation to the age-related changes in the positions of one or more of these three points. This tempting geometrical approach, designed by the authors [16] in order to describe the shape of the entire skull, might be a useful tool also for the study of the topographical relations of external to internal landmarks of the equine Cranium. Accordingly, the second major issue of the pilot study presented here was the application of a geometrical approach resembling that of Onar and Günes [16] in combination with the aforementioned computer-assisted measuring device, as was previously attempted by Ludwig [15]. The key feature of this approach was the formation and evaluation of virtual triangles composed of selected osseous POIs, which were used to analyse the relationships of intra- and extracranial POls.

\section{MATERIALS AND METHODS}

\section{Animals}

The skulls of 4 warmblood horses assigned to two age groups (young: 6 weeks, $n=2$; old: 14 and 17 years, $n=2$ ) were examined. The skulls were taken from the collection of the Institute of Anatomy of the University of Veterinary Medicine Hannover, Germany. Originally, the horses had been purchased from local animal trade companies to be used as specimens in the anatomical dissection classes of the University of Veterinary Medicine Hannover. They had been euthanased either prior to or immediately after their arrival, without being housed at the institute's facilities. All related procedures were performed in accordance with the German Federal Law, i.e. the Protection of Animals Act (Tierschutzgesetz §4, §7, $\S 7 \mathrm{a})$ as well as the Directive of the European Parliament and of the Council for the Protection of Animals Used for Experimental and other Scientific Purposes (2010/63/EU). 
Table 1. Selected points of interest (POIs), designated by capital letters at the outside (A, B, C) and small letters at the inside (a, b, c) of the equine skull. Previous publications $[1,15]$ had referred to the same POls, but had done so by using numbers or combinations of letters and numbers (see columns to the right; F, T, O, S, E: Os frontale, Os temporale, Os occipitale, Os sphenoidale, Os ethmoidale)

\begin{tabular}{llcc}
\hline POI & Description of location & Brucker [1] & Ludwig [15] \\
\hline Outside & & & F6 \\
A & $\begin{array}{l}\text { Most rostral point of the Linea temporalis (= most rostral point of the Processus zygomaticus } \\
\text { of the Os frontale in the Fossa temporalis) }\end{array}$ & 4 & T1 \\
B & Highest and also most caudal point of the Processus zygomaticus of the Os temporale & 16 & 01 \\
C & Most caudal and also most medial point of the skull, i.e. dorso-median at the Crista nuchae & & S1 \\
\hline Inside & & 17 & S5 \\
a & In the median plane on the Crista orbitosphenoidalis & 18 & E1 \\
b & In the median plane on the Crista sphenooccipitalis & 25 & \\
C & Most rostral point of the Cavum cranii (dorsal of the Fossa ethmoidalis) & & \\
\hline
\end{tabular}

Accordingly, notice of the horses' euthanasia for the purpose of organ removal from the dead animals (for subsequent anatomical studies) was given to The Animal Welfare Officer of the University of Veterinary Medicine Hannover prior to euthanasia, and was reconfirmed in the annual reports on all animals used within the period of the respective year. In accordance with the German Federal Law, i.e. the Protection of Animals Act (Tierschutzgesetz $§ 7$ ), explicit permission to perform this study was not necessary because no medical procedures or experiments were performed while the animals were alive, except intravenous injection for euthanasia. Euthanasia was performed by qualified and authorised medical staff by means of an initial general anaesthesia by $2 \%$ Isofluran (Isofluran CP $1 \mathrm{~mL} / \mathrm{mL}, \mathrm{CP}$-Pharma, Burgdorf, Germany) and a consecutive administration of $60 \mathrm{mg} / \mathrm{kg}$ Pentobarbital i.v. (Euthadorm ${ }^{\circledR} 400 \mathrm{mg} / \mathrm{mL}$, CP-Pharma, Burgdorf, Germany).

\section{Points of interest}

After maceration according to a protocol described in detail by Brucker [1] and Ludwig [15], the skulls were cut in the median plane, and one half of each skull (randomly either left or right) was used for the study. Six POls were defined and marked on each half skull with a pencil: (1) three external points easily and reproducibly palpable on a living horse; (2) three points at the inside of the Cavum cranii related to distinct neurological structures (Table 1, Fig. 1).

\section{Procedure of measurement/calculation}

The idea of the measurement setup was the transfer of the positions of the POIs on the skulls to a virtual 3D coordinate system, thereby enabling calculations with the data of these POls. Maintaining originally $3 D$ data in a (virtual) 3D environment avoids the problem of different perspective distortions, which occur in 2-dimensional (2D) (photographic) representations of 3D objects (Fig. 2). In the latter case, different perspectives may generate mistakable/deceiving impressions of the positions of the POIs, even though they have remained in the same location.

The device used for this purpose was the computer-assisted measurement arm FaroArm Fusion (FARO Europe ${ }^{\circledR}$, Stuttgart, Germany). The arm (Fig. 3) was mobile in 7 axes and - equipped with a narrow tip (inset in Fig. 3) - facilitated access even to POIs in intracranial positions that were difficult or impossible to reach with conventional methods $[1,15]$. The measurement procedure involved 7 steps.

\section{Calibration of the system and compilation of the protocol}

The measurement arm and the associated software DELCAM PowerINSPECT (DELCAM Birmingham, UK) were calibrated prior to the examination of each skull according to the procedure described in detail by Brucker [1] and Ludwig [15]. Then, a protocol was compiled, defining both the order in which the POIs had to be touched, and the calculations to be made with the resulting data.

\section{Positioning of the skulls}

For the measurements, the skull was placed on a polystyrene mat and adjusted in a standardised 


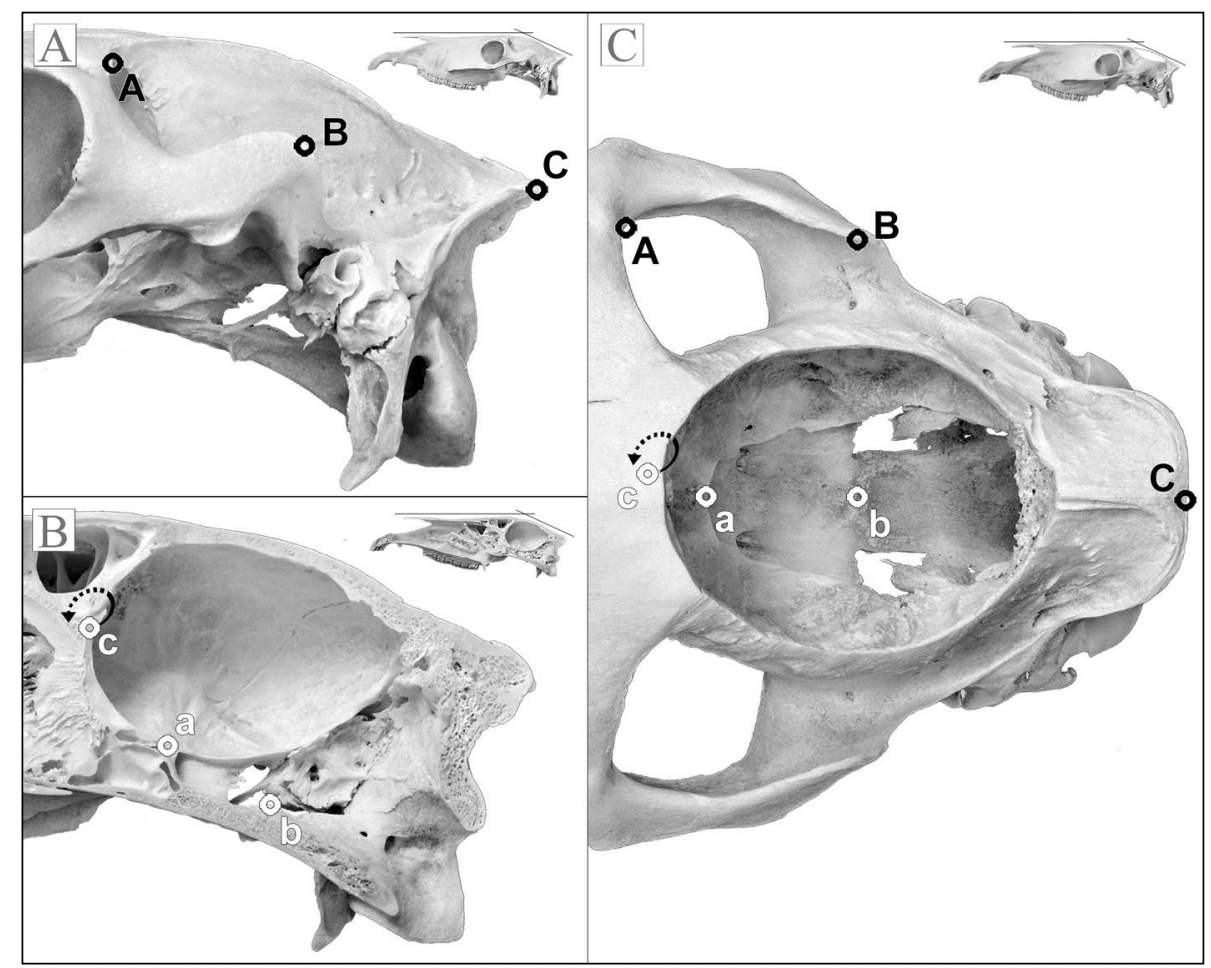

Figure 1. Photographical representation of equine skulls, all placed in a standardised position (note the horizontal line on the plane of the nose and forehead in the insets). Six points of interest (POIs), i.e. a, b, C, A, B, C, were selected; they are marked either in black (external surface) or in white (internal surface); A. Lateral aspect; B. Medial aspect; C. Dorsal aspect; here, the Calvaria has been removed in order to allow for a view onto the Basis cranii. Note that due to this positioning of the skull, the Basis cranii is always tilted caudo-ventrally, as is indicated by POls $a$ and $b$ in the medial aspect (B).

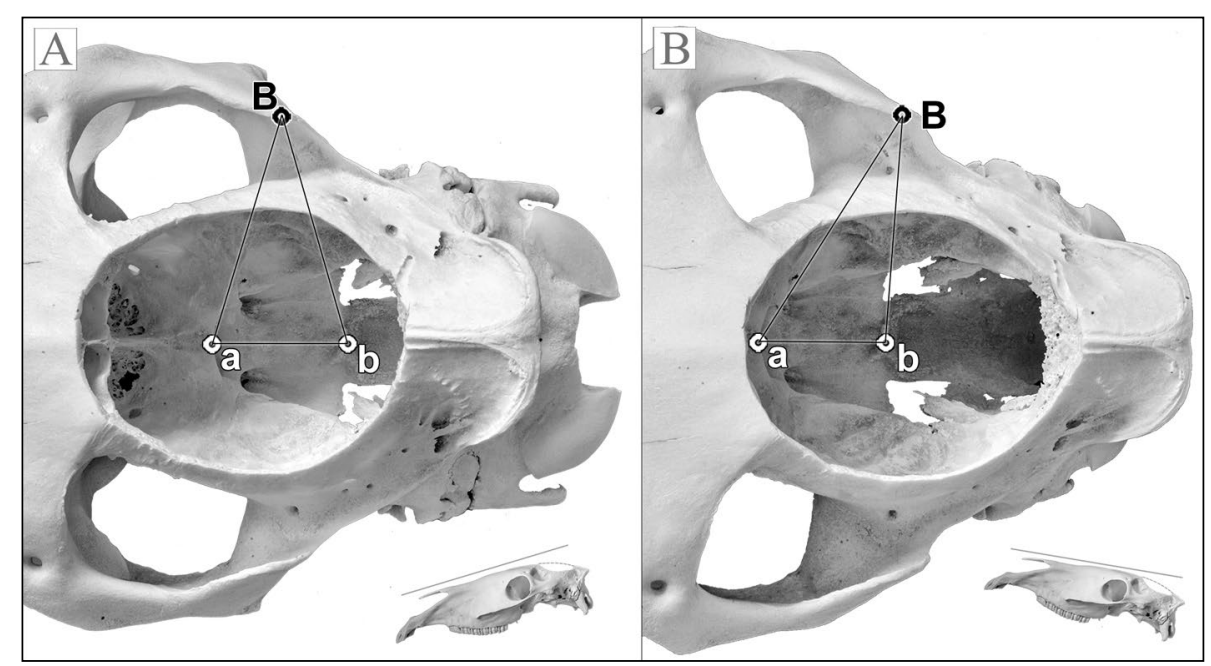

Figure 2. Illustration of the problem of perspective distortion created by the display of a 3-dimensional object in a 2-dimensional plane. Three points of interest (POIs), i.e. a, b, and B, are marked on a skull of which the Calvaria has been removed; in both figures, $\mathbf{A}$ and $\mathbf{B}$, the same skull is placed in two different positions (see insets): in panel $\mathbf{A}$ the skull is tilted rostro-ventrally, enabling a view into the rostral part of the Cavum cranii; in panel $\mathbf{B}$ the skull is tilted caudo-ventrally, enabling a view into the caudal part of the Cavum cranii. Due to the different perspectives, the positions of the POls seem to be different in the two panels: $\mathbf{A}$ and $\mathbf{B}$, even though they have remained in the same location. Accordingly, the shape of the triangles formed by connecting lines between the POls, is markedly different as well. 


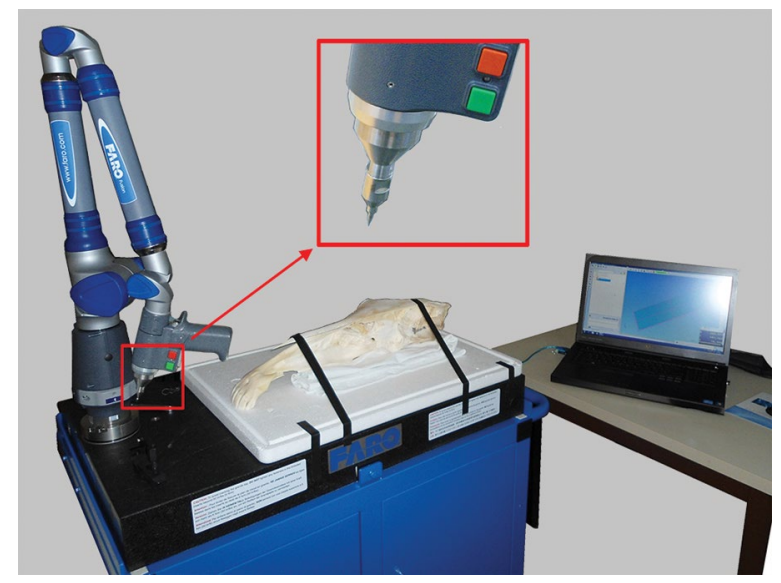

Figure 3. The FaroArm Fusion (FARO Europe ${ }^{\circledR}$, Stuttgart, Germany) and the experiment setup, with the right half of an equine skull placed and fixed (black fixation tape) on a polystyrene mat in a standardised position. Inset in the red box: magnified image of the tip of the measurement arm.

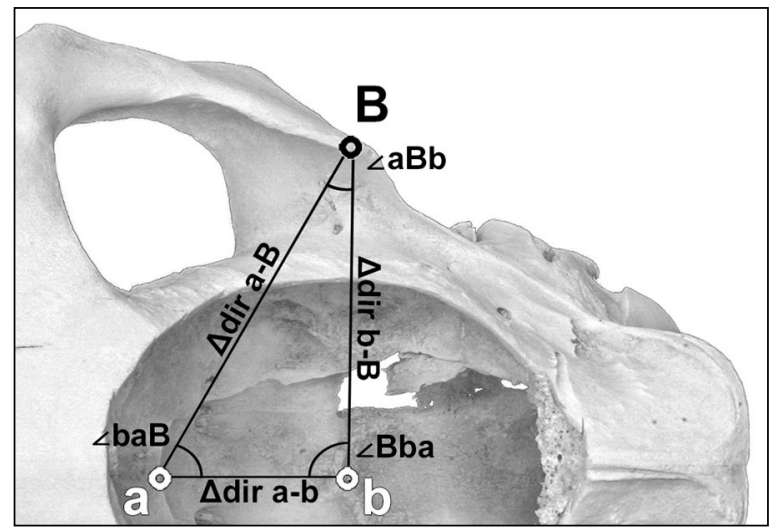

Figure 4. Dorsal aspect of the right half of an equine skull (Calvaria removed). The external point of interest (POI) B and the internal POls $a$ and $b$, respectively, were connected to form the virtual triangle $a-b-B$. The sides of the triangle represent the shortest, i.e. the direct, distances ( $\triangle$ dir) between the respective POls, e.g. $\triangle$ dir a-b. Two such distances form an inner angle, e.g. the angle $\angle \mathrm{baB}$, which is formed by the two distances $\triangle$ dir a-b and $\triangle$ dir $\mathrm{a}-\mathrm{B}$; the vertex of this angle at $\mathrm{POI} a$ is given in the middle of the term $\angle$ baB.

position - i.e. with the dorsal plane of the nose and forehead parallel to the surface of the table and with the median plane parallel to the edge of the table. This standard position was meticulously observed, because a tilt of the skull in any direction in space (Fig. 2) would have negatively influenced some of the parameters (e.g. the so-called indirect distances; see below). Therefore, the skulls were fixed in the proper position (Fig. 3) and kept immobile during the measuring process.

\section{Read-in of the data}

All six POls on the skull were touched with the tip of the measurement arm in the predefined order of the protocol, thereby transferring their $x-, y-$, and $z$-coordinates to the DELCAM PowerINSPECT software and automatically initialising the calculations. These coordinates of the POls were precise to three decimal places. All consecutive calculations were performed with these original data in order to avoid inaccuracies caused by rounding effects. However, for the presentation in the tables, the calculated data were rounded to a biologically meaningful degree of precision. (No statistical analyses were performed, as this pilot study aimed at demonstrating the applied technique of craniometry rather than the features of equine skull growth. For this reason, in order to keep things as simple as possible, only a small sample size was chosen, which, however, was not large enough to provide adequate data for a statistical analysis.)

\section{Calculation of the direct distances ( $\triangle$ dir)}

The DELCAM PowerINSPECT software calculated the so-called direct distances ( $\triangle$ dir), i.e. the shortest distance connecting two POls, using the read-in $\mathrm{x}-, \mathrm{y}-$, and $\mathrm{z}$-coordinates of the touched POIs.

\section{Formation of virtual triangles and calculation of angles}

The combination of the direct distances between three POls yielded virtual triangles (Fig. 4). Every triangle was characterised by the length of its sides (representing the direct distances $\triangle$ dir between the POIs) and by the triangle's three inner angles. The sizes of these inner angles were also calculated by the DELCAM PowerINSPECT software. In the tables and figures, these geometrical features were referred to by the following terminology: the triangle was named according to the designation of the POls involved (Table 1), e.g. triangle a-b-B (Fig. 4); two of its sides, representing for instance the direct distance $\triangle$ dir a-b and the adjacent $\triangle$ dir b-B, enclosed the inner angle named $\angle \mathrm{Bba}$; in this term, the letter in the middle position indicated the POI forming the vertex of this angle (here: POI b). The related figures display drawings of the triangles of the two age groups in order to visualise the extent of the shifts of the POls.

\section{Calculation of the indirect distances ( $\triangle$ long, $\triangle$ trans, $\Delta$ vert)}

The so-called indirect distances (Fig. 5) indicated how far a POI was located in front of another POI or 


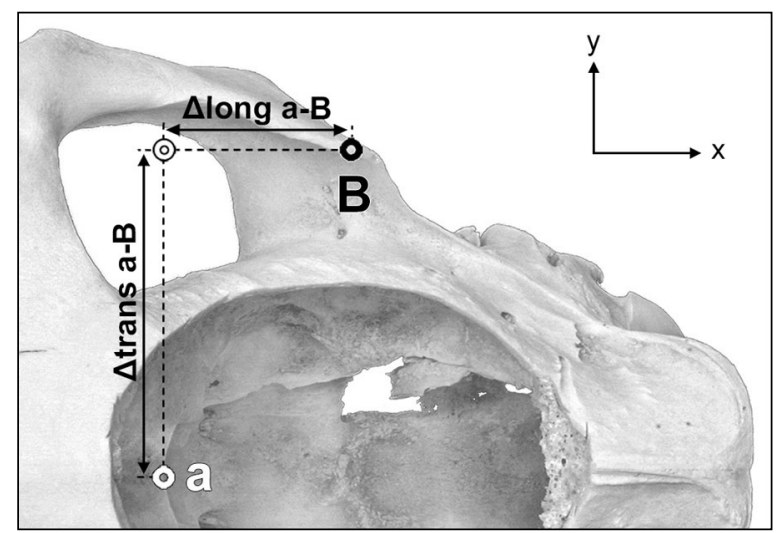

Figure 5. Dorsal aspect of the right half of an equine skull (Calvaria removed) to demonstrate the indirect distances, which extend along one of the three spatial axes, i.e. $x$-axis (longitudinal), $y$-axis (transversal), and z-axis (vertical). For instance, the indirect distance $\triangle$ long a-B indicates how far point of interest (POI) $B$ lies behind $\mathrm{POI} a$; $\triangle$ trans a-B indicates how far $\mathrm{POI} B$ lies away from points of interest $a$ in the lateral direction ( $y$-axis). The third indirect distance $\triangle$ vert a-B (z-axis) cannot be displayed in this dorsal aspect; however, it would indicate how far POI B lies above or below POI a.

behind it, how far above or below it, or how far medial or lateral of it (in other words: How far two POIs were separated from each other in the three spatial directions, i.e. on the $x-, y$ - or $z$-axis). The indirect distances were named $\triangle$ long (in the longitudinal direction, $x$-axis), $\triangle$ trans (in the transversal direction, $y$-axis) and $\triangle$ vert (in the vertical direction, z-axis) and were calculated with Microsoft EXCEL (Office 2010, Microsoft Corporation, Redmond, WA, USA) according to the procedure described in detail by Brucker [1].

\section{Graphical representation of the indirect distances between the POIs}

The coordinates of the POls of each age group were averaged using Microsoft EXCEL. The resulting two sets of coordinates (i.e. the mean values of the young group, and the mean values of the old group) were then transferred to the software GeoGebra 5.0 (freeware, Markus Hohenwarter, Salzburg, Austria), which graphically illustrated the positions of these averaged POIs in a 3D coordinate system. Within this software, the two sets of coordinates could then be shifted alongside one another, and were adjusted in two different positions: either with POI a in a hypothetically fixed position (hypothetical anchor point $\mathrm{POI} a)$, or with $\mathrm{POI} b$ in a hypothetically fixed position (hypothetical anchor point POI b). The figures created with the GeoGebra software present the positions of the POIs from four different aspects, and also illustrate the lengths of the indirect distances connecting these POIs.

\section{RESULTS}

Marked growth-related shifts of some POIs were detected, e.g. of the extracranial POI C, while shifts of others, e.g. of the intracranial POIs a and b, were relatively small. The shifts were characterised by distinct geometrical features of the virtual triangles, i.e. (1) by the size and shape of the triangles, thereby visualising the extent of a shift of a POI; (2) by the position of the triangles in 3D space $(x-, y-, z$-coordinates of the triangles' corners), indicating the direction of the shifts along the longitudinal, transversal, and horizontal axis of the skull.

\section{Extent of shifts as indicated by changes in size and shape of the virtual triangles}

The virtual triangles (Fig. 6), drawn with reference to the calculated direct distances (Table 2) and the corresponding calculated angles (Table 3 ), demonstrated whether the growth (extent of shifts of all three POIs of a triangle) was proportional or disproportional. These two kinds of growth were distinguished when comparing the outlines of the triangles in Figure 6 green outlines representing the mean values of the young skulls, and red outlines representing the mean values of the old skulls (Fig. 6).

A proportional growth had taken place when all POls of a triangle had shifted apart from each other to the same relative extent. Accordingly, a proportional growth was indicated by a paralle/ course of the green and red outlines of the triangles (Fig. 6). The impression of a parallel course depended on two features: firstly, on a close similarity of the inner angles of a green triangle and the corresponding red triangle; secondly, on the correlation between the size of an angle and the length of the related direct distances as follows. In a large triangle (with long sides, i.e. large direct distances between POIs), a small agerelated difference in the size of an angle had a great effect on the position of the POls at the ends of the corresponding triangle's sides (see for instance the position of the extracranial $\mathrm{POI} C$ in triangle $a-b-C$ in Fig. 6C). The opposite correlation applied for small triangles: When the sides of a triangle were short (small direct distances between the respective POIs), a large difference in angle size only accounted for small changes in the positions of the corresponding POls (see the intracranial POI $c$ in triangle $a-b-c$ 


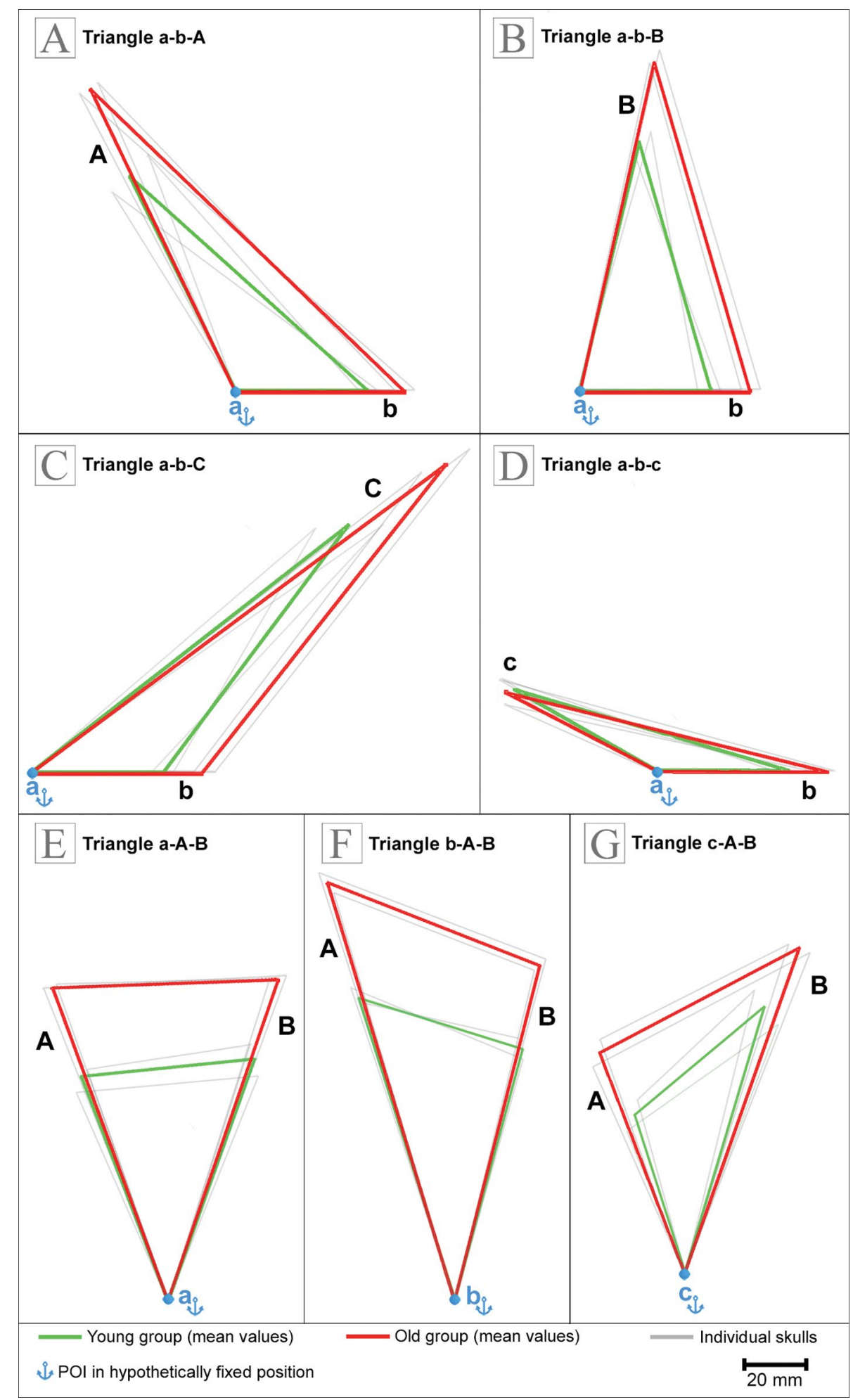

Figure 6. Graphical representation of the changes in size and shape of the triangles, demonstrating age-related shifts of points of interest (POIs) on the equine skull. The triangles were drawn according to both the measured direct distances ( $\triangle$ dir) between the POls (Table 2 ) and the corresponding calculated angles (Table 3); the size of the representation is approx. $50 \%$ of the original scale (see scale bar). Note that in this figure - like in any other 2-dimensional representation — the drawn object (in this case: the triangle) is placed in a graphical plane which neglects the objects 3-dimensional position in space. Consequently, the visible changes in size and shape illustrate the extent of a shift (compare the green and the red triangles), but cannot show the true spatial direction of the shifts. For reasons of better comparison, the triangles within each figure were arranged as follows: a hypothetically fixed anchor point was assigned (marked by a blue anchor symbol); triangles were mounted either on the same base line $a-b(\mathbf{A}-\mathbf{D})$, or on the same fixed POI a, b, or c (E-G). 
Table 2. Direct, i.e. shortest distances ( $\Delta$ dir) between the points of interest (POls) on the skulls of four horses in two age groups (young: $\mathrm{n}=2 ; 6$ weeks; old: $\mathrm{n}=2 ; 14$ and 17 years). All distances are given in millimetres $(\mathrm{mm})$. The calculations in this table were performed with the original measured values (which were precise to three decimal places). This fact explains the seeming discrepancies in the rounded presentation of some of the calculated values

\begin{tabular}{|c|c|c|c|c|c|c|c|c|c|}
\hline & $\triangle$ dir a-A & $\triangle$ dir b-A & $\triangle$ dir c-A & $\triangle$ dir a-B & $\triangle$ dir b-B & $\triangle$ dir c-B & $\Delta$ dir a-C & $\triangle$ dir b-C & $\triangle$ dir c-C \\
\hline \multicolumn{10}{|l|}{ Young group } \\
\hline Skull 1 (6 weeks) & 71 & 102 & 47 & 75 & 78 & 82 & 116 & 87 & 141 \\
\hline Skull 2 (6 weeks) & 76 & 97 & 55 & 83 & 82 & 90 & 134 & 105 & 167 \\
\hline Mean values & 74 & 99 & 51 & 79 & 80 & 86 & 125 & 96 & 154 \\
\hline \multicolumn{10}{|l|}{ Old group } \\
\hline Skull 3 (14 years) & 104 & 139 & 70 & 107 & 109 & 108 & 168 & 128 & 199 \\
\hline Skull 4 (17 years) & 103 & 132 & 77 & 104 & 105 & 107 & 152 & 116 & 183 \\
\hline Mean values & 103 & 135 & 73 & 105 & 107 & 107 & 160 & 122 & 191 \\
\hline \multirow[t]{2}{*}{ Difference in mean values } & 30 & 36 & 23 & 26 & 27 & 21 & 35 & 26 & 37 \\
\hline & $\triangle$ dir A-B & $\triangle \mathrm{dir} A-\mathrm{C}$ & $\triangle$ dir B-C & $\triangle$ dir a-b & $\triangle$ dir a-c & $\triangle$ dir b-c & & & \\
\hline \multicolumn{10}{|l|}{ Young group } \\
\hline Skull 1 (6 weeks) & 56 & 142 & 97 & 44 & 46 & 88 & & & \\
\hline Skull 2 (6 weeks) & 51 & 158 & 117 & 38 & 55 & 91 & & & \\
\hline Mean values & 53 & 150 & 107 & 41 & 51 & 89 & & & \\
\hline \multicolumn{10}{|l|}{ Old group } \\
\hline Skull 3 (14 years) & 75 & 207 & 142 & 56 & 56 & 108 & & & \\
\hline Skull 4 (17 years) & 66 & 187 & 130 & 50 & 50 & 99 & & & \\
\hline Mean values & 70 & 197 & 136 & 53 & 53 & 103 & & & \\
\hline Difference in mean values & 17 & 47 & 29 & 12 & 3 & 14 & & & \\
\hline
\end{tabular}

in Fig. 6D). According to these geometrical items, a proportional growth had occurred in the triangles displayed in Figures $6 \mathrm{~A}, \mathrm{~B}, \mathrm{E}$, and $\mathrm{F}$.

In contrast, non-parallel outlines of green or red triangles (Figs. 6C, D, G) were taken as a graphical equivalent of a disproportional growth. The latter was particularly distinct in triangle c-A-B (Fig. 6G): its inner angles differed with age by as much as $14.79^{\circ}$ at POI A ( $\angle C A B$, see Table 3$)$, and $4.95^{\circ}$ and $9.84^{\circ}$, respectively, at the other two $\mathrm{POls}$ of this triangle (Table 3). The significance of the proportional or disproportional shifts of the aforementioned POIs shall be discussed with regard to the anatomical characteristics of these POIs.

The differences between the individual skulls, i.e. inter-individual differences between the triangles within the same age group, were generally relatively large. In particular, the data of the two skulls of the young group differed more than the data of the two old skulls - especially as far as the sizes of the angles were concerned (Table 3), but also regarding the sizes of the direct distances (Table 2). The greatest individual differences in terms of shape (indicated by differences in the angles) was observed in the triangles $\mathrm{a}-\mathrm{b}-\mathrm{C}$ and c-A-B (compare their angle sizes within the young group in Table 3, and also compare the shapes of the grey triangles in Figs. $6 \mathrm{C}$ and $6 \mathrm{G}$ ). The greatest individual difference in size was found in the triangle $a-b-C$ of the young group: the length of its direct distances $\triangle$ dir a-C and $\triangle$ dir b-C (Table 2) varied strongly within the age groups - even though these inter-individual variations were smaller than the aforementioned age-related differences (Table 2) in this triangle. The special involvement of the extracranial POI C (at the Crista nuchae) in these cases of large inter-individual variability will be explained from the anatomical point of view in the discussion section.

Direction of shifts as indicated by the $x-, y-$, z-coordinates of the triangles (Figs. 7, 8; Table 4)

The comparative inspection of the different aspects (medial, rostral, dorsal) in Figures 7 and 8 
Table 3. Angles within the four triangles displayed in Figure 6. The point of interest (POI) at the vertex of the angle is located in the centre of the SYNTAX, e.g. $\angle \mathrm{baA}$ : inner angle at POI a in the triangle a-b-A. Data on the skulls of four horses in two age groups (young: $n=2 ; 6$ weeks; old: $n=2 ; 14$ and 17 years); all angles are expressed in degrees $\left({ }^{\circ}\right.$ ). The calculations in this table were performed with the original measured values (which were precise to three decimal places). This fact explains the seeming discrepancies in the rounded presentation of some of the calculated values

\begin{tabular}{|c|c|c|c|c|c|c|c|c|c|}
\hline & \multicolumn{3}{|c|}{ Triangle a-b-A (Fig. 6A) } & \multicolumn{3}{|c|}{ Triangle a-b-B (Fig. 6B) } & \multicolumn{3}{|c|}{ Triangle a-b-C (Fig. 6C) } \\
\hline & $\angle \mathrm{baA}$ & $\angle \mathrm{aAb}$ & $\angle A b a$ & $\angle$ baB & $\angle \mathrm{aBb}$ & $\angle \mathrm{Bba}$ & $\angle \mathrm{baC}$ & $\angle \mathrm{aCb}$ & $\angle \mathrm{Cba}$ \\
\hline \multicolumn{10}{|l|}{ Young group } \\
\hline Skull 1 (6 weeks) & 121.51 & 21.80 & 36.69 & 76.61 & 33.61 & 69.78 & 40.11 & 19.13 & 120.77 \\
\hline Skull 2 (6 weeks) & 110.41 & 21.91 & 47.69 & 74.24 & 26.94 & 78.83 & 34.50 & 12.02 & 133.48 \\
\hline Mean values & 115.96 & 21.85 & 42.19 & 75.42 & 30.27 & 74.31 & 37.30 & 15.57 & 127.12 \\
\hline \multicolumn{10}{|l|}{ Old group } \\
\hline Skull 3 (14 years) & 117.40 & 20.87 & 41.73 & 76.78 & 29.90 & 73.32 & 36.44 & 15.01 & 128.55 \\
\hline Skull 4 (17 years) & 113.99 & 20.46 & 45.54 & 77.48 & 27.98 & 74.55 & 37.23 & 15.28 & 127.50 \\
\hline Mean values & 115.70 & 20.67 & 43.64 & 77.13 & 28.94 & 73.93 & 36.83 & 15.14 & 128.02 \\
\hline \multirow[t]{3}{*}{ Difference in mean values } & 0.26 & 1.19 & 1.45 & 1.71 & 1.34 & 0.37 & 0.47 & 0.43 & 0.90 \\
\hline & \multicolumn{3}{|c|}{ Triangle a-b-c (Fig. 6D) } & \multicolumn{3}{|c|}{ Triangle a-A-B (Fig. 6E) } & \multicolumn{3}{|c|}{ Triangle b-A-B (Fig. 6F) } \\
\hline & $\angle$ bac & $\angle$ acb & $\angle$ cba & $\angle \mathrm{BaA}$ & $\angle \mathrm{aAB}$ & $\angle \mathrm{ABa}$ & $\angle \mathrm{BbA}$ & $\angle \mathrm{bAB}$ & $\angle \mathrm{ABb}$ \\
\hline \multicolumn{10}{|l|}{ Young group } \\
\hline Skull 1 (6 weeks) & 152.41 & 13.57 & 14.02 & 44.99 & 71.11 & 63.90 & 33.16 & 49.37 & 97.47 \\
\hline Skull 2 (6 weeks) & 149.27 & 12.54 & 18.19 & 36.63 & 79.31 & 64.06 & 31.57 & 57.75 & 90.69 \\
\hline Mean values & 150.84 & 13.05 & 16.11 & 40.81 & 75.21 & 63.98 & 32.37 & 53.56 & 94.08 \\
\hline \multicolumn{10}{|l|}{ Old group } \\
\hline Skull 3 (14 years) & 150.11 & 14.88 & 15.02 & 41.42 & 71.42 & 67.15 & 32.33 & 51.13 & 96.55 \\
\hline Skull 4 (17 years) & 155.97 & 12.02 & 12.01 & 37.19 & 71.94 & 70.87 & 29.64 & 51.98 & 98.38 \\
\hline Mean values & 153.04 & 13.45 & 13.51 & 39.31 & 71.68 & 69.01 & 30.98 & 51.56 & 97.46 \\
\hline \multirow[t]{3}{*}{ Difference in mean values } & 2.20 & 0.40 & 2.60 & 1.50 & 3.53 & 5.03 & 1.38 & 2.00 & 3.39 \\
\hline & \multicolumn{3}{|c|}{ Triangle C-A-B (Fig. 6G) } & & & & & & \\
\hline & $\angle \mathrm{BcA}$ & $\angle \mathrm{CAB}$ & $\angle A B C$ & & & & & & \\
\hline \multicolumn{10}{|l|}{ Young group } \\
\hline Skull 1 (6 weeks) & 41.66 & 104.97 & 33.37 & & & & & & \\
\hline Skull 2 (6 weeks) & 29.63 & 118.01 & 32.36 & & & & & & \\
\hline Mean values & 35.65 & 111.49 & 32.86 & & & & & & \\
\hline \multicolumn{10}{|l|}{ Old group } \\
\hline Skull 3 (17 years) & 43.55 & 96.33 & 40.12 & & & & & & \\
\hline Skull 4 (14 years) & 37.64 & 97.06 & 45.29 & & & & & & \\
\hline Mean values & 40.60 & 96.70 & 42.71 & & & & & & \\
\hline Difference in mean values & 4.95 & 14.79 & 9.84 & & & & & & \\
\hline
\end{tabular}

revealed that certain POls remained in a constant topographical relationship with each other on at least one of the three spatial axes (longitudinal, transversal, vertical).

For instance, the extracranial POI B was located on almost the same transversal plane as the intracranial $\mathrm{POI} b$ in both age groups. This was independent of the chosen fixed anchor point (compare Figs. 7A and $7 C$, and Figs. $8 \mathrm{~A}$ and $8 \mathrm{C}$, respectively): The longitudinal distance $\triangle$ long b-B was only $2 \mathrm{~mm}$ in the young group and $5 \mathrm{~mm}$ in the old group (Table 4); the arithmetic difference between these values indicated an age-related caudal shift of the extracranial POI B by as little as $3 \mathrm{~mm}$. (This situation applied when POI b was 


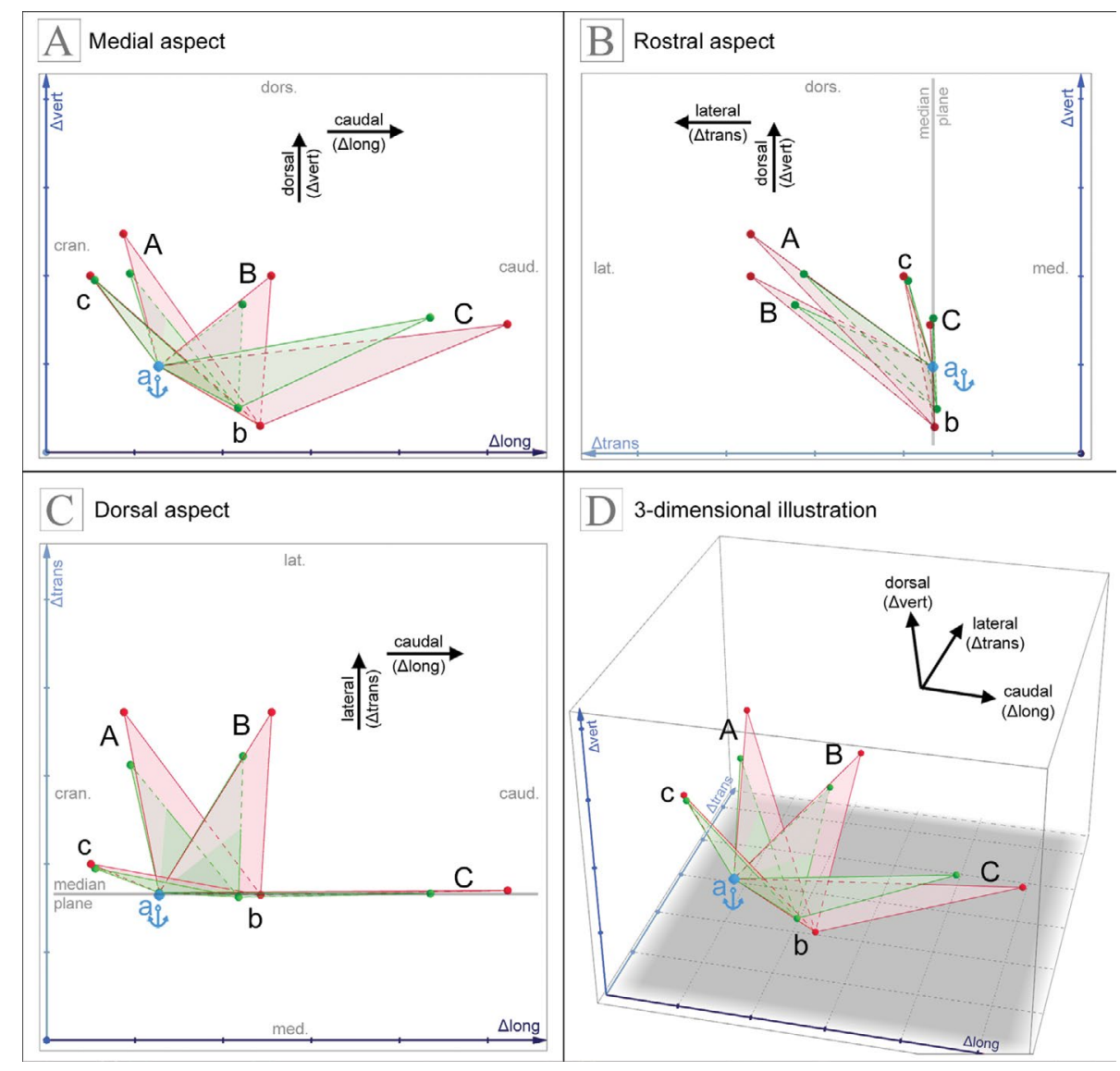

Figure 7. Graphical illustration to demonstrate the directions of shifts of points of interest (POls) on equine skulls of different ages (created with the software GeoGebra 5.0); A. Medial aspect to display shifts in the longitudinal and the vertical direction; B. Rostral aspect to display shifts in the transversal and the vertical direction; C. Dorsal aspect to display shifts in the longitudinal and the transversal direction; D. Graphical synopsis of panels $\mathrm{A}-\mathrm{C}$ in order to display the graphical relation of POls in 3-dimensional space. Keep in mind the perspective distortions in size and shape due to the oblique aspect chosen for this illustration. Each aspect displays four triangles that are the same as in Figures $6 A-D$, i.e. they are made up of $\mathrm{POI}$ c, $\mathrm{POI} A, \mathrm{POI}$, or $\mathrm{POI} C$ and are mounted on the baseline a-b. However, they are presented in their true (tilted) position in space, viewed from four different aspects, i.e. medial (A), rostral (B), dorsal (C), dorso-medio-caudal (3-dimensional illustration, D). Green triangles illustrate the mean values of the young group $(n=2 ; 6$ weeks), red triangles illustrate those of the old group $(n=2 ; 14$ and 17 years). Dashed lines and different shades of colour indicate overlapping areas of triangles (e.g. darker green areas are in front of pink areas, lighter green areas are behind). In all four aspects of this figure (A-D), POI a has been placed in a hypothetically fixed position (blue anchor symbol) and therefore remains in the same position in the two age groups. The differences in the positions of the green and red POls C, A, B, and C indicate the extent and directions of their age-related shifts in the topographical relation to the (hypothetically fixed) anchor point $\mathrm{POI}$ a.

taken as the fixed anchor point, as is the case in Figure 8 . When $\mathrm{POI}$ a was taken as the anchor point, as shown in Figure 7, the relation between POI B and POI $\mathrm{b}$ within each age group however still remained the same because both POls shifted together to the same extent with age.) And yet, the topographical relation between $\mathrm{POI} B$ and $\mathrm{POI} b$ did not remain constant because, at the same time, POI B shifted away from POI b both in the dorsal direction (Fig. 7A, 8A) and in the lateral direction (Fig. 7C, 8C), each by approx. $20 \mathrm{~mm}$ (Table 4). The resulting oblique, dorso-lateral shift of POI $B$ is indicated by the different sizes of the green and red triangles $a-b-B$ in Figures $7 \mathrm{~B}$ and $8 \mathrm{~B}$.
The aforementioned situation was in principle also true for the topographical relationship between the extracranial POI A and the intracranial anchor point POI a. There was, however, one exception concerning their position on transversal planes (Figs. 7A, 7C; 8A, 8C): irrespective of age, the extracranial $\mathrm{POI} A$ was always located rostral of the intracranial POI a: $\triangle$ long a-A was $12 \mathrm{~mm}$ in the young group and $16 \mathrm{~mm}$ in the old group. Accordingly, the shift of POI A away from $\mathrm{POI}$ a was very small (the difference in $\triangle$ long a-A of the young group and of the old group was only $4 \mathrm{~mm}$, see Table 4). However, like in POI $B$, there was a marked age-related shift of POI A in the dorso-lateral direction (Figs. 7B, 8B). 


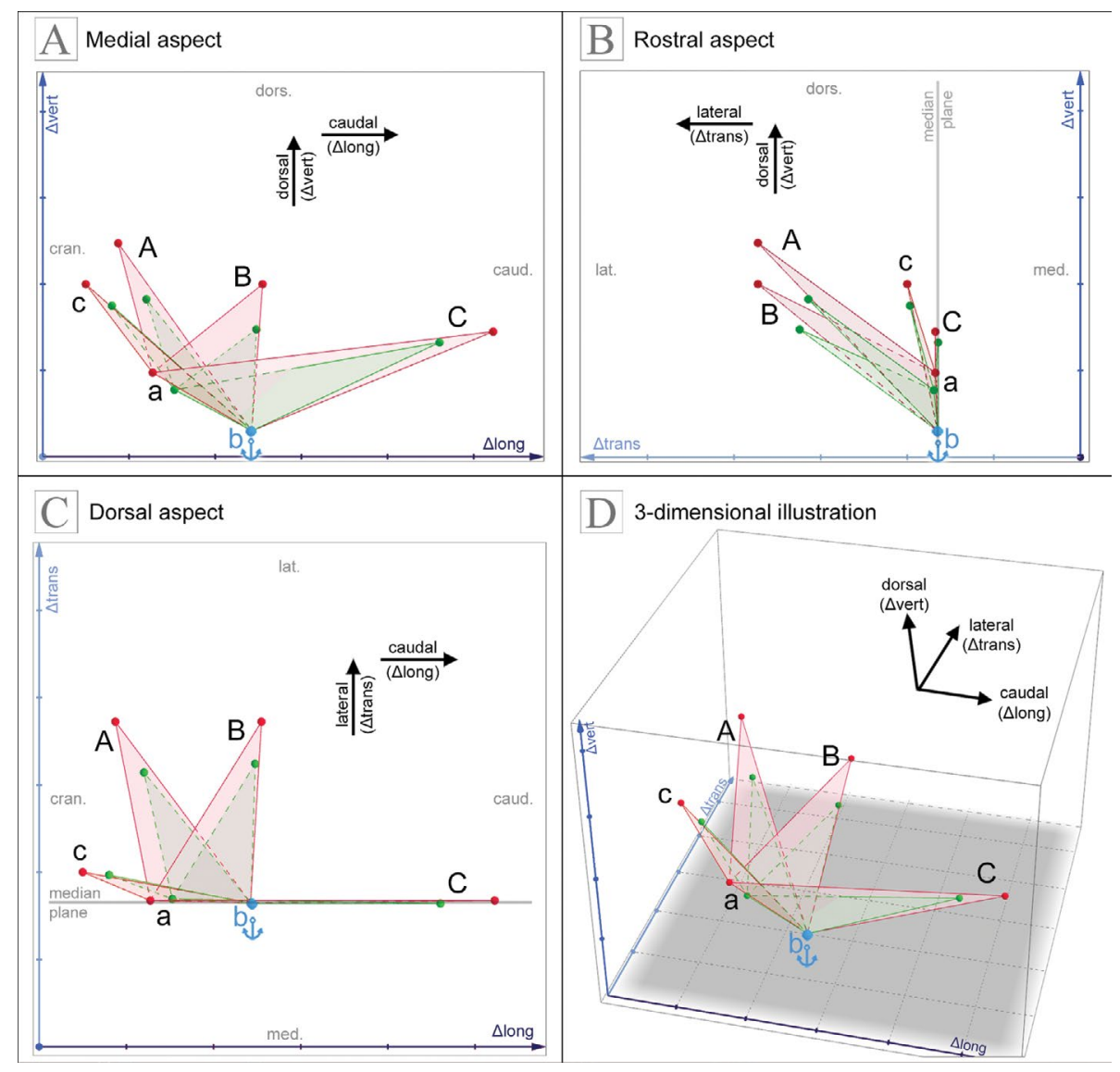

Figure 8. Graphical illustration to demonstrate the directions of shifts of points of interest (POls) on equine skulls of different ages (created with the software GeoGebra 5.0); A. Medial aspect to display shifts in the longitudinal and the vertical direction; B. Rostral aspect to display shifts in the transversal and the vertical direction; C. Dorsal aspect to display shifts in the longitudinal and the transversal direction; D. Graphical synopsis of panels A-C in order to display the graphical relation of POls in 3-dimensional space. Keep in mind the perspective distortions in size and shape due to the oblique aspect chosen for this illustration. Each aspect displays four triangles that are the same as in Figures $6 A-D$, i.e. they are made up of $\mathrm{POI}$ c, $\mathrm{POI} A, \mathrm{POI}$, or $\mathrm{POI} C$ and are mounted on the baseline a-b. However, they are presented in their true (tilted) position in space, viewed from four different aspects, i.e. medial (A), rostral (B), dorsal (C), dorso-medio-caudal (3-dimensional illustration, D). Green triangles illustrate the mean values of the young group $(n=2 ; 6$ weeks), red triangles illustrate those of the old group $(n=2 ; 14$ and 17 years). Dashed lines and different shades of colour indicate overlapping areas of triangles (e.g. darker green areas are in front of pink areas, lighter green areas are behind). In all four aspects of this figure (A-D), $P O I b$ has been placed in a hypothetically fixed position (blue anchor symbol) and therefore remains in the same position in the two age groups. The differences in the positions of the green and red POls C, A, B, and C indicate the extent and directions of their age-related shifts in the topographical relation to the (hypothetically fixed) anchor point POI $b$.

The largest age-related change in position was made by the extracranial POI C (Figs. 7A, 7C, 8A, 8C). Its shift occurred strictly in the caudal direction, as hardly any increase was measured in the vertical distance from the closest intracranial POI $b$ ( $\triangle$ long $\mathrm{b}-\mathrm{C}=26 \mathrm{~mm}$ vs. $\triangle$ vert $\mathrm{b}-\mathrm{C}=5 \mathrm{~mm}$; see Table 4). The extent of this shift on the longitudinal axis was large enough to maintain its caudal direction irrespective of the chosen intracranial anchor point POI a or POI b (compare Figs. 7A, 7C, 8A, 8C). (No shift of POI $C$ on the transversal axis was to be expected because - per definition (Table 1) - POI C, $\mathrm{POI} a$, and $\mathrm{POI} b$ were all located on the median plane. Small transversal distances between these POls, reported in Table 4, were due to inaccuracies in either the positioning of the skulls during the measurement procedure, or to slight inaccuracies in the position of the cut edge of the halves of the skull; the cut edge was supposed to represent the median plane of the entire skull.)

In contrast to the aforementioned extracranial POls A, B, C, the topographical relation of the intracranial $\mathrm{POI} c$ to its closest intracranial anchor point POI a (Fig. 7) was nearly independent of age: The indirect distances $\triangle$ long a-c, $\triangle$ trans a-c, and $\triangle$ vert a-c differed by no more than $2 \mathrm{~mm}$ with age (see 
Table 4. Selection of indirect distances between points of interest (POIs) a, b, c, A, B, C, of four equine skulls in two age groups (young $=6$ weeks; old $=14$ and 17 years). The indirect distance $\triangle$ long is the distance on the $x$-axis (longitudinal direction); the indirect distance $\triangle$ trans is the distance on the $y$-axis (transversal direction); the indirect distance $\triangle$ vert is the distance on the z-axis (vertical direction). All distances are given in millimetres $(\mathrm{mm})$. The calculations in this table were performed with the original measured values (which were precise to three decimal places). This fact explains the seeming discrepancies in the rounded presentation of some of the calculated values

\begin{tabular}{|c|c|c|c|c|c|c|c|c|c|c|}
\hline & $a-A$ & $a-B$ & $\mathrm{a}-\mathrm{C}$ & b-A & b-B & b-C & $a-b$ & $a-c$ & b-c & A-B \\
\hline \multicolumn{11}{|c|}{ Young group } \\
\hline \multicolumn{11}{|c|}{ Skull 1 (6 weeks) } \\
\hline$\triangle$ long & 13 & 40 & 114 & 52 & 1 & 75 & 39 & 25 & 64 & 53 \\
\hline$\triangle$ trans & 53 & 57 & 5 & 56 & 60 & 2 & 3 & 9 & 12 & 5 \\
\hline$\triangle$ vert & 46 & 28 & 22 & 68 & 50 & 44 & 21 & 37 & 59 & 18 \\
\hline \multicolumn{11}{|c|}{ Skull 2 (6 weeks) } \\
\hline$\triangle$ long & 12 & 38 & 132 & 46 & 3 & 97 & 35 & 33 & 68 & 49 \\
\hline$\triangle$ trans & 64 & 69 & 1 & 64 & 68 & 1 & 0 & 14 & 13 & 4 \\
\hline$\triangle$ vert & 39 & 28 & 22 & 56 & 45 & 38 & 16 & 42 & 59 & 11 \\
\hline \multicolumn{11}{|c|}{ Mean values } \\
\hline$\triangle$ long & 12 & 39 & 123 & 49 & 2 & 86 & 37 & 29 & 66 & 51 \\
\hline$\triangle$ trans & 58 & 63 & 3 & 60 & 64 & 1 & 2 & 11 & 13 & 4 \\
\hline$\triangle$ vert & 43 & 28 & 22 & 62 & 47 & 41 & 19 & 40 & 59 & 15 \\
\hline \multicolumn{11}{|c|}{ Old group } \\
\hline \multicolumn{11}{|c|}{ Skull 3 (14 years) } \\
\hline$\triangle$ long & 18 & 53 & 167 & 66 & 5 & 119 & 48 & 30 & 77 & 72 \\
\hline$\triangle$ trans & 81 & 83 & 3 & 82 & 84 & 3 & 0 & 15 & 15 & 2 \\
\hline$\triangle$ vert & 62 & 41 & 17 & 90 & 69 & 45 & 28 & 46 & 74 & 21 \\
\hline \multicolumn{11}{|c|}{ Skull 4 (17 years) } \\
\hline$\triangle$ long & 14 & 49 & 150 & 58 & 5 & 106 & 44 & 32 & 76 & 63 \\
\hline$\triangle$ trans & 83 & 81 & 1 & 83 & 82 & 1 & 1 & 12 & 12 & 2 \\
\hline$\triangle$ vert & 60 & 41 & 23 & 84 & 65 & 47 & 24 & 37 & 61 & 18 \\
\hline \multicolumn{11}{|c|}{ Mean values } \\
\hline$\triangle$ long & 16 & 51 & 159 & 62 & 5 & 113 & 46 & 31 & 77 & 67 \\
\hline$\triangle$ trans & 82 & 82 & 2 & 83 & 83 & 2 & 0 & 13 & 14 & 2 \\
\hline$\triangle$ vert & 61 & 41 & 20 & 87 & 67 & 46 & 26 & 41 & 68 & 20 \\
\hline \multicolumn{11}{|c|}{ Difference in mean values } \\
\hline$\triangle$ long & 4 & 13 & 35 & 13 & 3 & 26 & 9 & 2 & 11 & 16 \\
\hline$\triangle$ trans & 24 & 19 & 1 & 23 & 19 & 1 & 1 & 2 & 1 & 3 \\
\hline$\triangle$ vert & 18 & 13 & 2 & 25 & 20 & 5 & 7 & 1 & 9 & 5 \\
\hline
\end{tabular}

Table 4). However, the inter-individual differences in these distances were markedly larger than the agerelated differences (Table 4). In contrast, the distance between $\mathrm{POI} c$ and anchor point $\mathrm{POI} b$ on the longitudinal axis increased much more with age than the aforementioned distance between $\mathrm{POI} \mathrm{c}$ and $\mathrm{POI}$ a (the age-related difference in $\triangle$ long $\mathrm{b}$-c was $11 \mathrm{~mm}$; Table 4). The direction (rostral or caudal) of the shift of $\mathrm{POI} c$ in relation to $\mathrm{POI}$ a and $\mathrm{POI} b$ remained hypothetical, as it depended on the suggested anchor point (i.e. POI a or POI b): Either POI c moved rostrally (together with $\mathrm{POI}$ a) - if POI b was in a fixed position 
(Fig. 8C); or POI b shifted caudally, away from POI c, and away from the anchor point POI a (Fig. 7C).

In summary, the directions of the shifts depended on the chosen anchor point, unless the shifts were very large, i.e. larger than the increase in the distance between the two intracranial anchor points $\mathrm{POI}$ a and POI $b$ (Table 4): Regarding shifts of POIs on the longitudinal axis, their extent had to exceed a critical value of $9 \mathrm{~mm}$ (i.e. the age-related difference in $\triangle$ long a-b $=9 \mathrm{~mm}$; Table 4) in order to distinguish a shift in the rostral direction from a shift in the caudal direction. Regarding shifts on the vertical axis, their extent had to exceed a critical value of $7 \mathrm{~mm}$ (i.e. the age-related increase in $\triangle$ vert a-b $=7 \mathrm{~mm}$; Table 4) to in order to distinguish a ventral from a dorsal shift.

\section{DISCUSSION}

The technique and the specimens

This 3D morphometrical investigation was designed to focus on the technical and geometrical features of extra-intra craniometry. It was not meant at this time to elaborate on and present ontogenetic data of equine skull growth. This purpose required a choice of samples that was both small enough (in number) to remain easy to display, and at the same time differ enough (in size and shape of the skulls) to allow for a clear and straightforward demonstration of the technique itself. Accordingly, two skulls each were chosen from the two age groups which had been reported in previous studies $[1,15]$ to exhibit the strongest age-related differences: very young ( 6 weeks post partum) and old ( 14 and 17 years) horses.

The presentation of a 3D object (e.g. a skull) in a 2D display system (printed page, or monitor) is submitted to severe graphical limitations, as the task of visualisation has to cope with the inherent problem of perspective distortions. Such problems occur when geometrical data are taken from photographs, as was performed by Onar and Günes [16]. Working with the FaroArm Fusion avoids this problem because the data are true coordinates in 3D space. And yet, the problem reappears anyhow when it comes to displaying the data, e.g. the virtual triangles, in graphical representations. This may challenge the eye and the imagination of the beholder, especially when looking at images of virtual triangles that lie in an oblique position in space (i.e. in a position non-parallel to the three main spatial planes).

The precision and the technical reliability of the worldwide established FaroArm Fusion (www.faro. com) has been successfully demonstrated in previous, elaborate craniometrical studies [1, 15]. An important potential source of error, however, lies in the experiment setup: correct positioning of the skull on the measurement table of the FaroArm Fusion is crucial for an accurate recording of the data for the so-called indirect distances (distances along/parallel to the three main axes of space, i.e. longitudinal, transversal, vertical planes $[\mathrm{x}-, \mathrm{y}-, \mathrm{z}$-axis]). Even a slight tilting out of one of these planes will influence the measured value of the related indirect distances.

\section{Shifts of POIs}

The concept of analysing virtual triangles made up of three POIs is a further development of a technique introduced by Onar and Günes [16]. Their study was performed on photographs of the dorsal aspects of the skulls and, due to this technical approach, could only demonstrate shifts on the longitudinal and on the transversal axis, while shifts on the vertical axis could not be detected. Moreover, shifts in oblique 3D directions could not be appropriately recognised in these 2D photographs. Three-dimensionally oblique shifts, however, are supposed to reflect the true biological situation best [15]. The technique applied in this study was capable of detecting such oblique shifts. For instance, $\mathrm{POI} A$ and POI B (both on the Arcus zygomaticus) were both found to shift markedly in a latero-dorsal direction while remaining in an almost stable position on the longitudinal axis if analysed in relation to POI $a$ and $\mathrm{POI} b$ (these topographical relationships were clearly displayed by the virtual triangles $a-b-A$ and $a-b-B)$.

\section{Proportional versus disproportional growth}

Combining three POls in a virtual triangle, and evaluating all of the three angles (i.e. one inner angle at each of the three POIs) yielded data that was suited to distinguish between so-called proportional and disproportional types of growth. Proportional growth occurred when all of the three sides of a triangle grew by approximately the same relative extent, meaning that the respective parts of the skull increased in size, but did not change in their relative proportions. This applied, for instance, to POI B on the caudal edge of the Arcus zygomaticus in relation to the Basis cranii (POI a and POI b). The same was true for POI A (most rostral point of the Arcus zygomaticus) in relation to $\mathrm{POI} a$ and $\mathrm{POI} b$.

In contrast, the median point on the Crista nuchae (POI C) was subject to a large shift in the caudal 
direction (indicated by the disproportional change of triangle $a-b-C)$. This is in line with the functional relevance of this part of the skull: Differences in the prominence of the Crista nuchae have for instance been described in different breeds of dogs (muscular versus miniature breeds) to be correlated with the mass of the neck muscles of an animal [9].

The triangle a-b-c also displayed a disproportional type of growth, which was related to the intracranial POI c (the most rostral part of the Cavum cranii, dorsal to the Fossa ethmoidalis). In contrast to the extracranial POI C, however, the differences in the shape of this triangle marking this disproportional growth were not clearly age-related. Instead, they were caused by large individual differences in the position of $\mathrm{POI}$ c, which was located in a relatively large fossa, and was thus much more difficult to precisely determine than a $\mathrm{POI}$ on a well demarcated crista (like POI a and POI b).

\section{The anchor point(s)}

In this study, the description of the directions of shifts was always topographically relative, i.e. it focussed on the position of a selected POI in relation to the other two POls forming one virtual triangle. Intrinsically, the change in the position of such a triangle as a whole within the skull's outline remained unclear, as there was a lack of knowledge about a biologically (phylogenetically) truly stable centre point of the skull. The concept of using centroid size and Procrustes superimposition, as employed by Drake and Klingenberg [3], Drake [4], and Ge et al. [8] when comparing skulls of dogs and lagomorphs all in their adult state, was not adopted in our study in order not to neglect the age-related differences in size of the skulls. Consequently, the choice of an appropriate, i.e. topographically stable reference point was most desirable, but had to be attempted by a different approach. An ideal reference point (called anchor point in this study) would remain in its position, with the (Neuro-)Cranium growing around it. This problem was addressed by hypothetically choosing two alternatives of anchor points in the median plane of the Basis cranii, i.e. POI a (on the Crista orbitosphenoidalis) and POI b (on the Crista sphenooccipitalis), respectively (both with a strong clinical relevance due to their topographical relation to the pituitary gland and to most significant intracranial blood vessels).

The virtual triangles related to these hypothetical anchor points did prove both $\mathrm{POI} a$ and $\mathrm{POI} b$ to be remarkably stable in their positions (both in interindividual and age-group comparisons) in relation to the POls surrounding them. However, there were still some age-related differences of their positions, namely in the longitudinal direction, as indicated by the measures of the distance between them (i.e. $\Delta$ long a-b). The size of this distance increased by $9 \mathrm{~mm}$ when the values of the young group and of the old group were compared. Assuming that $\mathrm{POI}$ a was stable, $\mathrm{POI} b$ would have moved (by $9 \mathrm{~mm}$ ) in the caudal direction; assuming the contrary, $\mathrm{POI}$ a would have moved in the rostral direction. Between these extremes, the common overlapping range might be referred to as the reference area (anchor area) representing the fixed, i.e. unchanging part of the Basis cranii.

In order to further investigate this hypothesis, the consideration of histological data may be useful, as both POIs are related to synchondroses relevant for skull growth (POI being related to the Synchondrosis intersphenoidalis, POI b to the Synchondrosis sphenooccipitalis). The Synchondrosis intersphenoidalis is known to ossify prior to the Synchondrosis sphenooccipitalis in horses, i.e. at the age of 2-2.5 years vs. 3.25-6 years according to Ussow $[22,23]$. The bipolar structure of the Synchondrosis sphenooccipitalis in the growing skull of dogs [10] indicated a growth both in the rostral and in the caudal direction. A similar situation was seen in a preliminary study of these synchondroses in the skull of a warmblood foal [13].

Combining geometrical and (preliminary) histological findings one may suggest that prior to the time of closure of the Synchondrosis intersphenoidalis (i.e. up to 2-2.5 years), (neuro-)cranial growth originates from both synchondroses; this is the period when most of the growth of the neurocranium occurs $[1,14,15]$. Under the assumption that both synchondroses were equally active/productive, $\mathrm{POI}$ a and $\mathrm{POI} b$ would drift apart from each other to the same extent, and the true resting point (anchor point) would lie at half their distance, i.e. in the middle of the aforementioned anchor area. In horses older than 2.5 years (after ossification of the Synchondrosis intersphenoidalis) POI b may be regarded as the epicentre of growth processes and of shifts in the base of the Neurocranium.

\section{CONCLUSIONS}

The 3D evaluation of both extra- and intracranial osseous landmarks by means of virtual triangles served well as a geometrical tool applicable to reveal the topographical relationship between selected POIs. The results 
of this pilot study, although limited in their biological validity due to the small sample size, were suited to rule out some POls (e.g. POI C and POI c) as appropriate reference landmarks, and to recommend some others. For instance, from a practical point of view, the pair of POI A and $\mathrm{POI}$ a can serve as valuable reference points for the rostral part of the Cavum cranii, while the combination of POI B and POI $b$ are suited to refer to the caudal part of the Cavum cranii. As indicators for the probability of location of adjacent neurological structures and blood vessels, these POls are proposed as valuable landmarks that can help to optimise medical imaging procedures by employing a clearly defined approach. In this context, minimising the necessary acquisition time is a most desirable key issue in high quality magnetic resonance imaging of the equine brain $[20,21]$.

\section{REFERENCES}

1. Brucker P. Morphometrische Untersuchung des Hirnschädels vom Pferd mit einem computergestützten 3-dimensionalen Messsystem (doctoral dissertation). University of Veterinary Medicine, Hannover 2015.

2. Chrószcz A, Janeczek M, Pasicka E, et al. Height at the withers estimation in the horses based on the internal dimension of cranial cavity. Folia Morphol. 2014; 73(2): 143-148, doi: 10.5603/FM.2014.0021, indexed in Pubmed: 24902091.

3. Drake AG, Klingenberg CP. The pace of morphological change: historical transformation of skull shape in St Bernard dogs. Proc Biol Sci. 2008; 275(1630): 71-76, doi: 10.1098/rspb.2007.1169, indexed in Pubmed: 17956847.

4. Drake AG. Dispelling dog dogma: an investigation of heterochrony in dogs using 3D geometric morphometric analysis of skull shape. Evol Dev. 2011; 13(2): 204-213, doi: 10.1111/j.1525-142X.2011.00470.x, indexed in Pubmed: 21410876.

5. Driesch $\mathrm{A}$. von den. A guide to the measurement of animal bones from archaeological sites. Bulletins 1, Peabody Museum Bulletins, Harvard University. 1976: Harvard.

6. Duerst JU. Vergleichende Untersuchungsmethoden am Skelett bei Säugern. In: Abderhalden E (ed.). Handbuch der biologischen Arbeitsmethoden Abt VII, Methoden der vergleichenden morphologischen Forschung. Heft 2 . Urban u. Schwarzberg, Berlin, Wien. 1926.

7. Evans KE, McGreevy PD. Conformation of the equine skull: a morphometric study. Anat Histol Embryol. 2006; 35(4): 221-227, doi: 10.1111/j.1439-0264.2005.00663.x, indexed in Pubmed: 16836585.

8. Ge D, Yao L, Xia L, et al. Geometric morphometric analysis of skull morphology reveals loss of phylogenetic signal at the generic level in extant lagomorphs (Mammalia: Lagomorpha). Contrib Zool. 2015; 84: 267-284.

9. Klatt B. über den Einflu\ der Gesamtgröle auf das SchÄdelbild nebst Bemerkungen über die Vorgeschichte der Haustiere. Archiv für Entwicklungsmechanik der Organismen. 1913; 36(3): 387-471, doi: 10.1007/bf02266725.

10. Klingler M. Retrospektive Betrachtung des Fugenschlusses der Synchondrosen der Schädelbasis bei Hunden verschiedener Rassen unter besonderer Berücksichtigung des Cavalier King Charles Spaniels (doctoral dissertation). University of Giessen 2013.

11. Komosa M, Moliński K, Godynicki S. The variability of cranial morphology in modern horses. Zoolog Sci. 2006; 23(3): 289-298, doi: 10.2108/zsj.23.289, indexed in Pubmed: 16603822.

12. Krahmer R. Messungen am Kopfskelett des Pferdes. Ein Beitrag zur Bedeutung der Kraniologie, Leipzig 1963.

13. Lang A, Gasse H. Preliminary histological study on synchondroses in the skull of a warmblood foal. Unpublished data. 2016.

14. Löffler K. Untersuchungen über die Wachstumsverhältnisse der Kopfknochen des Pferdes (doctoral dissertation). University of Giessen 1919.

15. Ludwig M. Computergestützte Craniometrie beim Pferd unter Berücksichtigung altersabhängiger Lageverschiebungen osteologischer Landmarks (doctoral dissertation). University of Veterinary Medicine, Hannover 2015.

16. Onar V, Güneş $H$. On the variability of skull shape in German shepherd (Alsatian) puppies. Anat Rec A Discov Mol Cell Evol Biol. 2003; 272(1): 460-466, doi: 10.1002/ ar.a.10052, indexed in Pubmed: 12704704.

17. Osborn HF. Craniometry of the equidae. In: Memoirs of the American Museum of natural history. New Series, Vol. 1, Part III. 1912: 55-100.

18. Radinsky L. Allometry and reorganization in horse skull proportions. Science. 1983; 221(4616): 1189-1191, doi: 10.1126/ science.221.4616.1189, indexed in Pubmed: 17811522.

19. Reeve E, Murray P. Evolution in the horse's skull. Nature. 1942; 150(3805): 402-403, doi: 10.1038/150402a0.

20. Stuckenschneider K. Magnetresonanztopograhische Untersuchungen der Gehirnregion gesunder und neurologisch erkrankter Pferde mit einer Feldstärke von 3 Tesla (doctoral dissertation). University of Veterinary Medicine, Hannover 2013.

21. Stuckenschneider K, Hellige M, Feige $K$, et al. 3-Tesla magnetic resonance imaging of the equine brain in healthy horses - Potentials and limitations. Pferdeheilkunde Equine Medicine. 2014; 30(6): 657-670, doi: 10.21836/ pem20140605.

22. Ussow SS. Über Alters- und Wachstumsveränderungen am Knochengerüst der Haussäuger. Arch Wiss Prakt Tierhk. 1901; 27: 339-394.

23. Ussow SS. Über Alters- und Wachstumsveränderungen am Knochengerüst der Haussäuger. Arch Wiss Prakt Tierhk. 1902; 28: 113-137. 